\title{
Lonely Me, Lonely You: Loneliness and the Longitudinal Course of Relationship Satisfaction
}

\author{
Marcus Mund $^{1}$ (iD $\cdot$ Matthew D. Johnson ${ }^{2}$
}

Published online: 12 March 2020

(c) The Author(s) 2020

\begin{abstract}
Individuals feel lonely when they perceive a discrepancy between the amount of closeness and intimacy in social relationships they desire and what they actually experience. Across several studies, partner relationships have consistently been found to be the most powerful protective factor against loneliness. Previous research on this topic, however, has exclusively focused on loneliness as a concomitant or outcome of low relationship quality, but not as a predictor in its own right, which is surprising given the trait-like features of loneliness. In the present study, we investigated the role of loneliness in predicting later levels and the development of relationship satisfaction over a period of 8 years in a heterogeneous sample of 2337 stable couples drawn from the German Family Panel. By applying ActorPartner Interdependence Models and dyadic response surface analyses, we found that loneliness evinced substantial negative actor and partner effects on relationship satisfaction and its development over 8 years. Furthermore, we found that women were most satisfied with their relationships when both partners scored low on loneliness, whereas men were most satisfied when their own loneliness was low, irrespective of their partners' loneliness. Congruently low levels of loneliness between women and men as well as declines in loneliness of at least one partner were additionally associated with increases in relationship satisfaction over time.
\end{abstract}

Keywords Loneliness · Similarity · Relationship satisfaction · Partner relationships · Dyadic response surface analysis

Electronic supplementary material The online version of this article (https://doi.org/10.1007/s1090 2-020-00241-9) contains supplementary material, which is available to authorized users.

Marcus Mund

marcus.mund@gmail.com

1 Institut für Psychologie, Friedrich-Schiller-Universität Jena, Humboldtstraße 11, 07743 Jena, Germany

2 Department of Human Ecology, University of Alberta, 302 Human Ecology Building, Edmonton AB T6G 2N1, Canada 


\section{Introduction}

Individuals are motivated to form and maintain close and meaningful relationships with others (Baumeister and Leary 1995) and not accomplishing this goal often results in the experience of loneliness. More specifically, loneliness arises when individuals perceive their social relationships as deficient in either quantitative or qualitative aspects (Ernst and Cacioppo 1999; Perlman and Peplau 1981). Loneliness has manifold negative consequences for personal health and well-being (for reviews, see Ernst and Cacioppo 1999; Hawkley and Cacioppo 2010; Heinrich and Gullone 2006; HoltLunstad et al. 2015) and has, thus, also become an important issue for policy makers (Jo Cox Commission on Loneliness 2017).

A large body of research has been devoted to identifying contextual and individual factors promoting or protecting against loneliness (e.g., Bosma et al. 2015; Ernst and Cacioppo 1999; Luhmann and Hawkley 2016). Among these factors, partner relationships stand out as the single most powerful factor protecting individuals from being lonely (Dykstra and Fokkema 2007; Flora and Segrin 2000; Green et al. 2001; Luhmann and Hawkley 2016; Stack 1998; Tornstam 1992). However, a series of crosssectional (Ayalon et al. 2013; de Jong Gierveld et al. 2009; Givertz et al. 2013; Hsieh and Hawkley 2018; Knoke et al. 2010; Moorman 2016; Stokes 2017a) and longitudinal (Stokes 2017b) studies has shown that not all partner relationships protect against loneliness. Specifically, loneliness might even be promoted through the partner relationship if it is seen as unsatisfying or of otherwise low quality. In empirical terms, prior studies have shown consistent negative associations between relationship quality and loneliness. However, these studies suffer from several limitations.

First, previous research focused on the association between loneliness and relationship satisfaction in married couples. Marriage, however, has become less normative during the last few decades and might have become subject to strong selection effects (Neyer et al. 2014). In Germany for example, where the data used in the present study were gathered, the number of marriages dropped from 516,388 (6.5 per 1000 inhabitants) in 1990 to 400,115 (4.9 per 1000 inhabitants) in 2015 (Statistisches Bundesamt 2016). As a consequence, the results from prior studies might not be generalizable to a broader population. To obtain more generalizable results, it is necessary to include partner relationships of any kind, including both married and unmarried couples. Second, previous studies on loneliness and partner relations have focused on couples in midlife or old age (e.g., Ayalon et al. 2013; de Jong Gierveld et al. 2009; Givertz et al. 2013; Hsieh and Hawkley 2018; Moorman 2016; Stokes 2017a). As a consequence, the couples assessed in previous studies had long relationship histories, which might make it difficult to observe changes in either relationship satisfaction or loneliness since both might have previously stabilized. Third, prior work has treated loneliness as a concomitant or outcome of low relationship quality (e.g., Ayalon et al. 2013; Givertz et al. 2013; Hsieh and Hawkley 2018; Knoke et al. 2010; Moorman 2016; Stokes 2017b). In the present study, we consider loneliness as a risk factor for low relationship satisfaction in its own right. This line of reasoning is based on several studies implying that loneliness is a rather stable phenomenon with a wide variety of intra- and interpersonal consequences. 


\subsection{Loneliness as a Predictor of Relationship Satisfaction}

It has been shown in several recent studies that loneliness is a construct capturing robust differences between individuals (Mund et al. 2019, 2020). This stability of inter-individual differences is an important prerequisite for a characteristic to operate as a predictor of other variables (Fridhandler 1986; Kraemer et al. 1994). Specifically, a recent metaanalysis has shown that inter-individual differences in loneliness across the lifespan are as stable as inter-individual differences in personality characteristics such as the Big Five or self-esteem (Mund et al. 2020). In addition, another study using data from four nationally representative samples has shown that between 50 and $60 \%$ of inter-individual differences in loneliness can be attributed to stable, trait-like sources (Mund et al. 2019). Finally, from a behavior genetic point of view, approximately $40 \%$ of the phenotypic variation in loneliness has been found to be accounted for by genotypic variation (for reviews, see Goossens et al. 2015; Spithoven et al. 2019). Taken together, this line of research suggests that inter-individual differences in loneliness are largely stable over time. As a characteristic with stable inter-individual differences, loneliness should be capable of predicting several life outcomes (Fridhandler 1986; Kraemer et al. 1994). Indeed, the predictive power of loneliness has been documented in a large body of research with a particular focus on health-related outcomes (for reviews, see Ernst and Cacioppo 1999; Hawkley and Cacioppo 2010; Heinrich and Gullone 2006; HoltLunstad et al. 2015). However, despite its intrinsically social and interpersonal nature, surprisingly little is known about the interpersonal features and long-term relationship outcomes associated with loneliness.

It should be noted that, in addition to such person effects, relationship effects can be expected. That is, it is likely that features of the relationship might retroact on and evoke subsequent changes in loneliness (Mund et al. 2016; Neyer et al. 2014). However, in the present study, we focus on the effects of loneliness on later levels and the development of relationship satisfaction.

\subsection{Similarity in Loneliness and Relationship Satisfaction}

Partner relationships are inherently interdependent dyadic relationships. That is, both partners influence each other and construe their evaluation of the relationship based on their own and their partner's personality characteristics and behaviors (Mund et al. 2016). The effects of partner similarity on relationship outcomes such as satisfaction and stability has been investigated in a number of studies. The results of this line of research have been inconsistent, ranging from non-existent to medium-sized effects (Dyrenforth et al. 2010; Gonzaga et al. 2007; Watson et al. 2004). For example, by using profile correlations in a study with 66 couples, Gonzaga et al. (2007) found correlations between similarity in personality traits and relationship satisfaction ranging from $r=.28$ (agreeableness) to $r=.34$ (extraversion). In two representative studies from Australia and Great Britain, in contrast, Dyrenforth et al. (2010) found no (Great Britain) or only minor effects of similarity (Australia) using both profile correlations and discrepancy scores ( $\beta$ s ranging between -.058 and .082). A similar picture was found in the study by Watson et al. (2004). By using absolute difference scores, no effects of similarity on relationship satisfaction emerged for women, and only two small-sized correlations were found for men ( $r=.019$ for openness and $r=.016$ for conscientiousness). 
Discrepancy scores and profile correlations have been the main analysis tools for assessing questions on partner similarity and relationship satisfaction. However, both of these approaches have several methodological drawbacks (for detailed discussions, see Edwards 1993; Schönbrodt et al. 2018). Most strikingly, they are confined to linear conceptualizations of similarity in a sense that congruently high scores on a given characteristic are assumed to be always more beneficial than congruent scores at low or moderate levels of a given characteristic. However, it might well be that partner similarity might be associated with relationship satisfaction in a non-linear fashion. This would be the case when only congruence at moderate levels of a characteristic would be beneficial, while congruence on either the high or the low end of a personality dimension would be associated with lower levels of satisfaction.

Dyadic response surface analysis has been proposed as an alternative approach to investigate the effects of dyadic similarity of a given characteristic, such as loneliness, on relationship satisfaction. In principle, dyadic response surface analyses estimate the association of all observed dyadic combinations (e.g., Partner A low, Partner B high; both partners high; Partner A moderate, Partner B low, etc.) on a predictor (e.g., loneliness) and its effect on an outcome variable (e.g., relationship satisfaction). In this way, dyadic response surface analysis provides a nuanced view on partner (dis)similarity and relationship satisfaction (Schönbrodt et al. 2018). This method has already been applied to investigate the association between the Big Five personality traits and several aspects of relationship quality (Leikas et al. 2018; van Scheppingen et al. 2019; Weidmann et al. 2017; Zhou et al. 2017). In a study with 141 couples, for example, Weidmann et al. (2017) found relationship satisfaction of men to be particularly high when the men and their spouses were either congruently low or congruently high in neuroticism. Incongruence, in contrast, was found to be negatively associated with relationship satisfaction, as was congruence on medium levels of neuroticism (Weidmann et al. 2017). To the best of our knowledge, however, dyadic response surface analysis has not been used to investigate the effects of partner similarity in loneliness on relationship satisfaction and its development.

\section{The Present Study}

In the present study, we investigated the prospective effects of loneliness on relationship satisfaction in several ways. First, we examined whether loneliness would predict later levels of relationship satisfaction in couples. Second, we investigated whether loneliness predicted the development of relationship satisfaction across several years. Third, we examined the effects of (dis)similarity of partners in their levels of loneliness at the outset of the study on later levels and the development of relationship satisfaction. Finally, we investigated whether similarity between partners in the development of loneliness would be associated with the development of relationship satisfaction across several years. All these questions were investigated in a dyadic fashion, considering the intra- and interpersonal effects (Kenny et al. 2006).

Based on prior research on the association between personality characteristics and the Big Five (Mund et al. 2016; Weidmann et al. 2016), we expected negative actor- and partner-effects of loneliness on relationship satisfaction and its development. As we are the first to investigate the effects of similarity in loneliness on relationship satisfaction, we refrained from formulating specific hypotheses regarding the resulting pattern. This part of the analysis should, thus, be considered exploratory. 


\section{Method}

\subsection{Participants}

The data for the present study were taken from the first eight waves (which we will refer to as W1 through W8 in the remainder) of the German Family Panel (pairfam; Brüderl et al. 2017; Huinink et al. 2011). This study is funded as a long-term project by the German Research Foundation and, as such, has been approved by Institutional Review Boards (IRB). As a consequence, German regulations allow researchers to analyze the scientific use file (Brüderl et al. 2017) without acquiring additional IRB approvals.

In the study, which started in 2008 and is still ongoing, 12,402 anchor participants are interviewed yearly at their homes by trained interviewers. The respondents are asked about a wide variety of topics, including about their mental health and partner relations. Some of the questions are discussed face-to-face via a computer-assisted personal interview. Other, more private topics (e.g., use of contraceptives, health, but also personality) are assessed via a computer-assisted self-administered interview, which means that these questions are answered directly by the interviewees via a handheld computer (Huinink et al. 2011). In addition to the interviewed anchor participants, their partners are sent questionnaires upon consent (for more information, see Johnson et al. 2017, 2018). This multi-actor design allows us to combine data from both the anchors and their partners into a dyadic dataset (Kenny et al. 2006). For the present study, we used data from 2,337 stable heterosexual couples (i.e., anchor participants and their partners) who provided data on at least three measurement occasions.

At the first measurement occasion, women were 30.53 years old on average ( $\mathrm{SD}=$ $6.53)$ and men had an average age of 31.90 years $(\mathrm{SD}=5.77)$. Couples were together for $8.53(\mathrm{SD}=5.90)$ years at $\mathrm{W} 1$, on average, ranging from zero to 34.92 years. Among women, 1417 (61\%) were married, 837 (35.27\%) were not married; 62 (2.60\%) were divorced from a former spouse, and $21(0.91 \%)$ were widowed. Among men, 2303 individuals provided information on their marital status. Of those, $1412(61.18 \%)$ were married, $792(34.32 \%)$ were unmarried, 60 (2.60\%) were divorced, and 39 (1.69\%) were widowed. Most of the married men and women (98.45\%) were married with their current partner, the remaining $1.65 \%$ were separated from a former spouse, but in a new relationship. In the vast majority of couples (84.21\%), the partners shared a common household. On average, couples had 1.15 children $(\mathrm{SD}=1.15$, median $=1)$, ranging from zero to ten children. Converted into US Dollars, the monthly net household income amounted to approximately 3200 USD ( $S D=1560.55$ median $=2868.63)$, ranging from 172 to $16,456.91$ USD.

\subsection{Measures}

\subsubsection{Loneliness}

Loneliness was assessed using a single item ("I feel lonely") answered on a Likert-type rating scale ranging from 1 (not at all) to 5 (absolutely). Single items are among the most frequently used measures of loneliness (Mund et al. 2020; Pinquart and Sörensen 2001). Nevertheless, several authors have raised severe criticism against single-item measures in general (Diamantopoulos et al. 2012) and regarding loneliness in particular (Marangoni 
and Ickes 1989; Daniel Russell 1982). However, there is much evidence in favor of the appropriateness of single-item measures of loneliness.

First, single-item measures such as the one used here are highly correlated with multiitem questionnaires of loneliness such as the 20-item UCLA Loneliness Scale (Dan Russell et al. 1978) and its shorter forms (Hughes et al. 2004; Iecovich 2013). Second, the results of studies employing single-item measures of loneliness converge very well with studies using multiple items. For instance, the results of two studies on loneliness and mortality (e.g., Patterson and Veenstra 2010; Shiovitz-Ezra and Ayalon 2010) that used even different single-item measures converge very well with each other and with the results of a comprehensive meta-analysis on this topic incorporating a wide variety of loneliness measures (Holt-Lunstad et al. 2015). Likewise, a recent meta-analysis on the stability and change of loneliness found no differences between single- and multi-item measures of loneliness with respect to patterns of mean-level change and rank-order stability (Mund et al. 2020). In a similar vein, a recent study on the sources of inter-individual differences in loneliness also found strong convergence between three different versions of single-item measures employed in nationally representative samples from Germany, Switzerland, and Australia (Mund et al. 2019). Finally, Mund and Neyer (2019) found considerable convergence between a single-item measure of loneliness and an 11-item version of the de Jong Gierveld Loneliness Scale in predicting levels of the Big Five across a time period of 4 years. Third, there is substantial overlap between the nomological networks of single- and multi-item measures of loneliness. For example, von Soest et al. (2020) reported virtually identical correlations with demographic and health-related variables for a singleitem measure of loneliness and a 3-item version of the de Jong Gierveld Loneliness Scale. Taken together, we conclude that single-item measures of loneliness demonstrate a considerable amount of convergent validity with multi-item measures. Given all these findings, we conclude that single-item measures of loneliness are valid and appropriate.

In pairfam, loneliness was assessed at measurement waves 1, 4, 5, 7, and 8; for the present analyses, we only used data on loneliness collected at W1 and W8. These two occasions were chosen because we wanted to examine the effects of changes in loneliness on changes in relationship satisfaction. In the analytical framework that we will describe in more detail below, it is only possible to incorporate changes in loneliness as residualized change between two measurement occasions.

\subsubsection{Relationship Satisfaction}

At each measurement occasion, relationship satisfaction was assessed using a single item from the Relationship Assessment Scale (Hendrick et al. 1998): "Overall, how satisfied are you with your relationship?" Respondents answered on a Likert-type rating scale ranging from 0 (very dissatisfied) to 10 (very satisfied). This item closely corresponds to other commonly-used single item measures of relationship satisfaction in couple research (e.g., Johnson et al. 2018; Rhoades et al. 2012). As relationship satisfaction was assessed at every wave, we used all available data points to model change in relationship satisfaction over time.

\subsubsection{Covariates}

Age and relationship duration (in years) were included as demographic covariates in the analyses. Shyness and depressiveness were included as additional covariates because they 


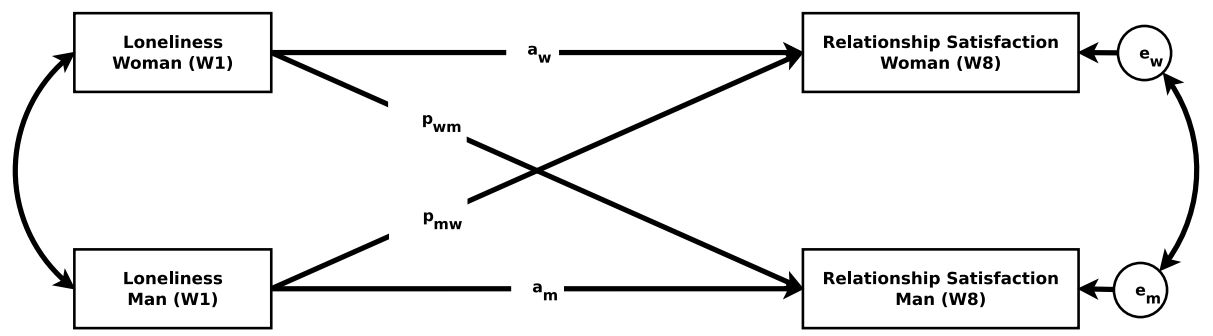

Fig. 1 APIM employed to predict levels of relationship satisfaction at W8 by loneliness at W1. Paths labelled a denote actor effects, paths labelled b represent partner effects. Subscript $\mathrm{m}$ denotes effects for men, subscript $\mathrm{w}$ denotes effects for women. The figure is licenced under CC-BY 4.0 International and is available at https://osf.io/tjuay/

most closely resemble neuroticism and extraversion. Neuroticism and extraversion could not be included as covariates because they were not measured in pairfam along with loneliness. However, while depressiveness can be considered a facet of neuroticism (McCrae and Costa 2008), shyness entails aspects of both neuroticism and extraversion (Asendorpf 1990).

Shyness was measured using three items ("I feel inhibited in the presence of others"; "I feel shy in the presence of others"; "I approach other people easily", reverse coded) answered on Likert-type rating scale ranging from 1 (not at all) to 5 (absolutely). Coefficient $\omega$, which we used as an indicator of scale reliability (McNeish 2018), amounted to .747 for women (95\% confidence interval ranging from .726 to .769) and .733 for men (95\% confidence interval ranging from .710 to .756 ), respectively.

Depressiveness was assessed using a single item ("How often did you feel down and melancholy in the past four weeks?") answered on a Likert-type rating scale ranging from 1 (never) to 5 (always). ${ }^{1}$ Supplemental Tables S2 and S4 show the results for all models without covariates.

\subsection{Analysis Strategy}

\subsubsection{Loneliness and Relationship Satisfaction}

We used Actor-Partner Interdependence Models (APIM; Kenny et al. 2006) as depicted in Fig. 1 as the basic tool to examine our research questions. With APIM, it is possible to disentangle actor and partner effects. In the case at hand, actor effects denote to what extent an individual's loneliness at the first measurement occasion is associated with this individual's own relationship satisfaction at W8. Partner effects denote to what extent an individual's loneliness at W1 is capable of predicting his or her partner's relationship satisfaction at W8 (Kenny et al. 2006).

\footnotetext{
1 We also ran models including household income, cohabitation, and number of children in the household. The results were identical to the models containing only shyness, depressiveness, age, and relationship duration. Complete model results for both sets of covariates can be found at https://osf.io/tjuay/.
} 


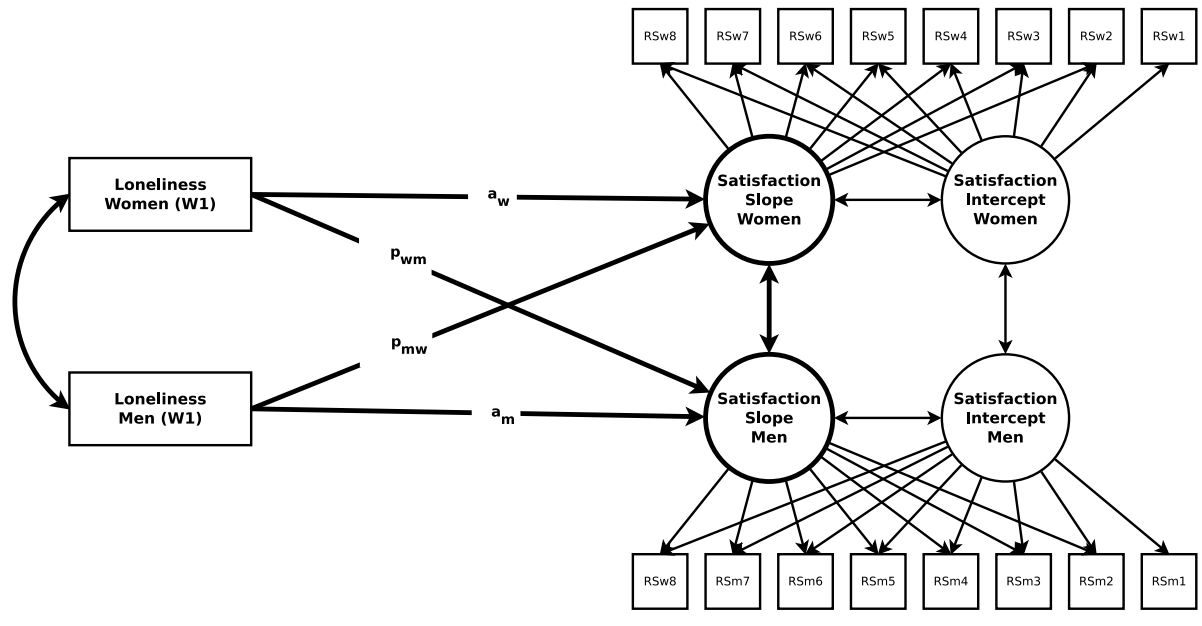

Fig. 2 APIM employed to predict the development of relationship satisfaction across 8 years by loneliness at W1. Paths labelled a denote actor effects, paths labelled b represent partner effects. Subscript m denotes effects for men, subscript w denotes effects for women. The figure is licenced under CC-BY 4.0 International and is available at https://osf.io/tjuay/

With the APIM, we examined whether loneliness at W1 is associated with relationship satisfaction at W8 as well as with the development of relationship satisfaction across the 8 years of the study period. For the latter question, the APIM was adapted as shown in Fig. 2. To examine the development of relationship satisfaction across the 8 years of the study period, we employed latent basis growth models (Ram and Grimm 2007). Specifically, we fixed the first slope loading to 0 and the last loading to 1 . In this way, the mean of the slope reflects the overall amount of change that has occurred from W1 through W8.

\subsubsection{Effects of Similarity}

The effects of dyadic similarity in loneliness on later levels and the development of relationship satisfaction were examined using dyadic response surface analysis (DRSA; Schönbrodt et al. 2018; Weidmann et al. 2017), which is a combination of APIM and response surface analysis (see Fig. 3). DRSA extends the canonical APIM by adding higher-order polynomials of the predictor variables to the model. Specifically, in addition to the actor and partner effects included in the APIM, DRSA adds squared actor and partner effects as well as an interaction term between the actor's and the partner's levels on the predictor variable (see Fig. 3 and Supplemental Figures S1 and S2; statistical details are provided in the Online Supplement).

The interpretation of results obtained with DRSA is primarily based on response surface parameters, which are derived from the coefficients estimated in the extended APIM (see Fig. 3; Schönbrodt et al. 2018, for more information, see the Online Supplement at https://osf.io/tjuay/). The response surface parameters are visualized with a response surface plot. There are four response surface parameters for women $\left(a_{1 f}, a_{2 f}, a_{3 f}, a_{4 f}\right)$ and men $\left(a_{1 m}, a_{2 m}, a_{3 m}, a_{4 m}\right)$, respectively. These parameters characterize two essential features of DRSA: First, the line of congruence (LOC), where values of X (e.g., woman's loneliness) are identical to Y (e.g., man's loneliness). As such, the LOC illustrates the effects of 


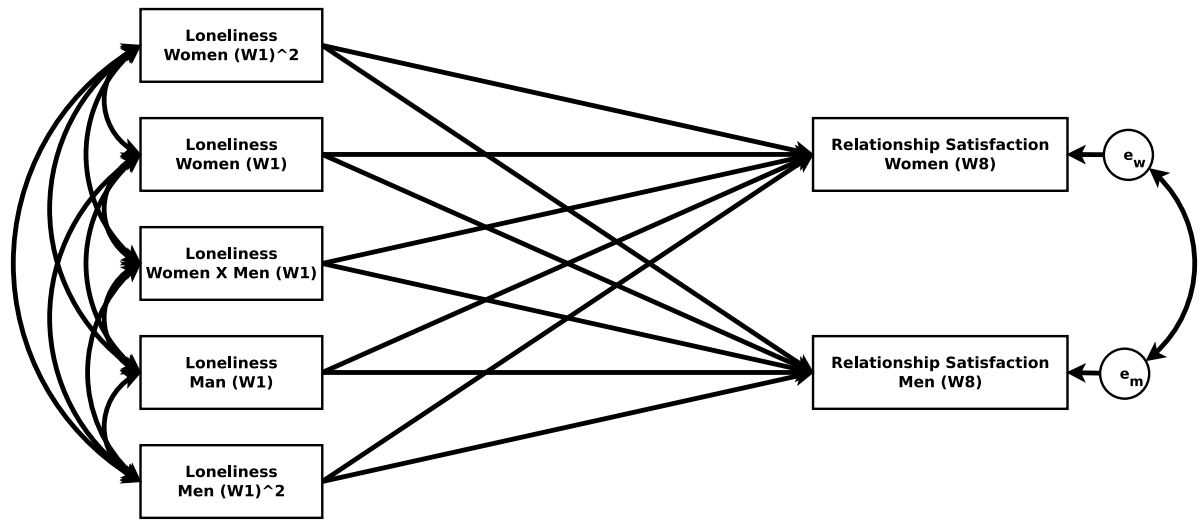

Fig. 3 Extended APIM to conduct a dyadic response surface analysis. With this model, we examined effects of dyadic similarity in loneliness at W1 on levels of relationship satisfaction at W8. The figure is licenced under CC-BY 4.0 International and is available at https://osf.io/tjuay/

congruence (i.e., common scores) on the outcome variable (e.g., relationship satisfaction). The response surface parameter $a_{1}$ describes whether the LOC is linear or flat; $a_{2}$ contains information on the curvature of the LOC. For example, a significantly positive $a_{2}$-parameter would indicate that the LOC is u-shaped and, thus, that congruence on either high or low levels of the predictor (e.g., loneliness) is particularly beneficial for the outcome (e.g., relationship satisfaction). Second, the line of incongruence (LOIC) illustrates the effects of both partners being incongruent on the predictor variable (i.e., $X=-Y$; for example, woman scoring high on loneliness, man scoring low). The parameters $a_{3}$ and $a_{4}$ describe linear and non-linear trends for the LOIC, respectively (Schönbrodt et al. 2018).

All APIM and DRSA were examined in two steps. In the first step, we set up an unconstrained model in which all parameters were estimated freely. In the constrained model, we forced all actor and partner effects to be equal for women and men. Subsequently, we evaluated whether the constrained model fit the data worse than the unconstrained model via a $\chi^{2}$-difference test. A nonsignificant $\chi^{2}$-difference test indicates that the regression coefficients can be considered invariant across women and men and that there are no sex differences in the association between loneliness and relationship satisfaction.

All models were analyzed with the lavaan package (Rosseel 2012) for R (R Core Team 2018). The response surfaces were plotted using the R package RSA (Schönbrodt 2017). APIM and DRSA were run using robust maximum likelihood estimators (MLR); missing data were treated with Full Information Maximum Likelihood (Enders 2010). The models were considered to show a good (reasonable) fit to the data when the ratio of $\chi^{2}$-to-df was smaller than 2 (3), the Comparative Fit Index (CFI) exceeded 0.97 (0.95), and both the Root Mean Square Error of Approximation (RMSEA) and the Standardized Root Mean Square Residual (SRMR) fell below 0.05 (0.08; Schermelleh-Engel et al. 2003) All analysis scripts and the complete model outputs are available at https:/osf.io/tjuay/. 
Table 1 Descriptive statistics and zero-order correlations for all study variables at W1

\begin{tabular}{|c|c|c|c|c|c|c|c|c|c|c|}
\hline \multirow[t]{2}{*}{ Variable } & \multicolumn{2}{|c|}{ Women } & \multicolumn{2}{|l|}{ Men } & \multicolumn{6}{|c|}{ Correlations } \\
\hline & $\mathrm{M}$ & SD & $\mathrm{M}$ & SD & 1 & 2 & 3 & 4 & 5 & 6 \\
\hline 1 Loneliness & 1.65 & 1.01 & 1.41 & 0.81 & .06 & -.23 & .26 & .29 & .01 & -.01 \\
\hline 2 Relationship satisfaction & 8.33 & 1.96 & 8.40 & 1.90 & -.25 & .21 & -.19 & -.09 & .02 & -.01 \\
\hline 3 Depressiveness & 2.42 & 0.94 & 2.18 & 0.92 & .31 & -.15 & .10 & .20 & .04 & .03 \\
\hline 4 Shyness & 2.22 & 0.88 & 2.10 & 0.84 & .31 & -.09 & .21 & .02 & -.08 & .05 \\
\hline 5 Age & 30.53 & 6.53 & 31.90 & 5.77 & -.03 & -.05 & -.06 & -.07 & - & .56 \\
\hline 6 Relationship duration & 8.53 & 5.90 & 8.53 & 5.90 & -.07 & -.06 & -.07 & -.03 & .67 & - \\
\hline
\end{tabular}

Correlations below the diagonal show associations within women; correlations for men are displayed above the diagonal. Associations between partners of a couple are displayed in the diagonal (boldface). Correlations set in italics have a $p$ value $>.05$

\section{Results}

\subsection{Descriptive Statistics}

Table 1 provides an overview of means, standard deviations, and intercorrelations of all variables measured at W1 separately for women, men, and couples. Supplemental Table S1 presents means and standard deviations for loneliness at W8 as well as for relationship satisfaction from W2 through W8 Women reported being lonelier $(d=0.26)$, more depressive $(d=0.26)$, more shy $(d=0.14)$, and younger $(d=-0.22)$ than men. Regarding relationship satisfaction, no substantial differences were observed $(d=-0.04)$ between women and men.

There were no substantial sex differences in the correlations between the study variables. On the couple-level, the correlation between both partners' loneliness was very small $(r=.06)$, although statistically significant. Furthermore, relationship satisfaction and depressiveness were moderately correlated between couple members, while there was no significant correlation between partners' shyness.

\subsection{Univariate Growth Curves}

As a precursor to our predictive models, we first computed univariate growth curves for men and women's relationship satisfaction. Both the models for women (CFI $=0.986$, RMSEA $=$ $\left.0.029, \mathrm{SRMR}=0.037, \chi^{2} / d f=2.14\right)$ and for men $(\mathrm{CFI}=0.982, \mathrm{RMSEA}=0.031, \mathrm{SRMR}$ $=0.037, \chi^{2} / d f=2.18$ ) had a very good fit to the data. The results of the latent growth model are displayed in Supplemental Figure S3. For women, relationship satisfaction decreased by 0.624 scale points $(p<.001)$ across the 8 years, which reflects a decrease of 0.45 standard deviations. For men, relationship satisfaction decreased by 0.593 scale points $(p<.001)$ across the study period. In terms of effect size, this decrease equals 0.43 standard deviations.

In addition, we also ran growth curves for loneliness. Given the single item measure and the inclusion of only two measurement occasions, these models were saturated. Loneliness increased for both women $(0.163$ scale points; $d=0.16 ; p<.001)$ and men $(0.186$ scale points; $d=0.23 ; p<.001)$ across the 8 years of the study. 
Table 2 Loneliness as predictor of later levels and development of relationship satisfaction (APIM)

\begin{tabular}{|c|c|c|c|c|c|c|}
\hline \multirow[t]{2}{*}{ Effect } & \multirow[t]{2}{*}{ EST } & \multicolumn{2}{|l|}{$95 \% \mathrm{CI}$} & \multirow[t]{2}{*}{$p$} & \multirow{2}{*}{$\beta_{q}$} & \multirow{2}{*}{$\beta_{\sigma}$} \\
\hline & & LB & UB & & & \\
\hline \multicolumn{7}{|c|}{ Predicting later levels of relationship satisfaction } \\
\hline Actor & -0.317 & -0.424 & -0.210 & $<.001$ & -.163 & -.128 \\
\hline Partner & -0.189 & -0.271 & -0.107 & $<.001$ & -.078 & -.095 \\
\hline \multicolumn{7}{|l|}{ Correlations } \\
\hline Loneliness W1 & .034 & -.010 & .077 & .126 & - & - \\
\hline Satisfaction W8 & .394 & .319 & .469 & $<.001$ & - & - \\
\hline \multicolumn{7}{|c|}{ Predicting development of relationship satisfaction } \\
\hline Actor & -0.180 & -0.264 & -0.096 & $<.001$ & -.124 & -.101 \\
\hline Partner & -0.153 & -0.217 & -0.090 & $<.001$ & -.085 & -.107 \\
\hline \multicolumn{7}{|l|}{ Correlations } \\
\hline Loneliness W1 & .035 & -.009 & .078 & .115 & - & - \\
\hline Satisfaction slopes & .603 & .439 & .766 & $<.001$ & - & - \\
\hline
\end{tabular}

$N=2337$ couples. EST For actor and partner effects, unstandardized regression weights are reported. All models are controlled for age of the participants, relationship duration, shyness, and depressiveness.

\subsection{Loneliness Effects on Relationship Satisfaction}

\subsubsection{Later Levels of Relationship Satisfaction}

To determine whether loneliness predicts later levels of relationship satisfaction as well as its development over time, we used the APIM as depicted in Fig. 1. As recommended by Kenny et al. (2006), we first ran a model with no equality constraints on either the actor or the partner effects. We then compared this model to a model with actor and partner effects constrained to be equal. This constrained model did not fit worse than the unconstrained model $\left(\Delta \chi^{2}=0.120, \Delta d f=2 ; p=.942\right)$, indicating that there are no differences between women and men with regard to the influence of loneliness on later levels of relationship satisfaction. Furthermore, the constrained model had an excellent fit to the data, as indicated by a CFI of 0.988, an RMSEA of 0.022 (90\% CI 0.009-0.034), an SRMR of 0.015, and a $\chi^{2} / d f$ ratio of 2.09 .

The results, which are displayed in the upper part of Table 2, indicate that individuals who felt lonelier than others at the first measurement occasion were less satisfied than others with their relationship 8 years later (actor effect). Furthermore, the partners of those who felt lonelier than others at the first measurement occasion were likewise less satisfied with their relationship than the partners of less lonely individuals (partner effect). At the first measurement occasion, loneliness was uncorrelated between the partners, whereas the within-couple correlation in relationship satisfaction at W8 was of medium size.

In addition to these key analyses, we ran two sets of supplemental analyses. First, we ran the models for married $(n=1394)$ and unmarried $(n=933 ; 10$ couples did not report marital status) couples separately. Second, we split the sample into two groups based on relationship duration at the first measurement occasion. The first group ( $n=617$ couples) included couples who were together for less than 4 years. The second group ( $n=649$ couples) consisted of couples who were together for more than 11 years. Regarding marital 
status, there were no differences in the association between loneliness and later levels of satisfaction. Regarding relationship length, the actor effect of loneliness on later levels of satisfaction was not statistically significant in the group with a relationship length of less than 4 years, whereas the partner effect was significant. In contrast, the actor, but not the partner effect was statistically significant in the group with a relationship duration of more than 11 years. The initial correlation between the partners in loneliness was not significant in the group with the shorter relationship duration, whereas it was significant in the group with a longer relationship history. The correlation in relationship satisfaction tended to be stronger in the group with a longer relationship duration, but it was significantly positive in both groups. Despite these differences in statistical significance, it should be noted that the parameter estimates in both groups did not differ from each other (see Supplemental Figures S4 and S5 and model outputs at https://osf.io/tjuay/).

\subsubsection{Development of Relationship Satisfaction}

In a second set of analyses, we predicted the development of relationship satisfaction over 8 years from loneliness measured at baseline. As in the previous analysis, the model in which actor and partner effects were constrained to be equal for women and men did not fit worse than the unconstrained model $\left(\Delta \chi^{2}=1.614, \Delta d f=2, p=.446\right)$. Furthermore, the constrained model showed an overall good fit to the data as indicated by a CFI of 0.924 , an RMSEA of 0.030 (90\% CI 0.028-0.032), an SRMR of 0.048 , and a $c h i^{2} / d f$ ratio of 3.08 .

The results of this model are displayed in the lower half of Table 2. Taking the general decreasing trend of relationship satisfaction into account, the results indicate that individuals who feel lonelier than others at the first measurement occasion decrease even faster in relationship satisfaction than less lonely individuals. Again, the partner effect reached statistical significance as well and indicate that the relationship satisfaction of partners of individuals feeling lonelier than others decreases faster than the satisfaction of those partnered with less lonely individuals. Loneliness was uncorrelated between the partners at the first measurement occasion. However, the development of relationship satisfaction was highly interdependent among couple members, as indicated by the large correlation between the slopes.

In the supplemental analyses, no differences in the parameter estimates emerged for married versus unmarried couples. However, the initial correlation between partners in loneliness was significant in the couples with a relationship duration of more than 11 years, whereas it was not significant for the couples with shorter relationships (i.e., $<4$ years). However, despite this difference in statistical significance, the parameters did not significantly differ from each other (see Supplemental Figures S6 and S7 and model outputs at https://osf.io/tjuay/).

\subsection{Similarity in Loneliness and Relationship Satisfaction}

\subsubsection{Later Levels of Relationship Satisfaction}

In this analysis, we examined the effects of dyadic similarity in loneliness at the first measurement occasion on each partners' level of relationship satisfaction 8 years later. As with the ordinary APIM, we first examined whether the relevant paths of the model could be set equal for men and women. The results of the comparison between the constrained and the unconstrained model indicated differences in how similarity in loneliness affects 
Table 3 Response surface parameters estimated from the dyadic response surface analyses

\begin{tabular}{|c|c|c|c|c|c|c|c|c|}
\hline \multirow[t]{2}{*}{ Parameter } & \multicolumn{4}{|l|}{ Women } & \multicolumn{4}{|l|}{ Men } \\
\hline & EST & LB & UB & $p$ & EST & LB & UB & $p$ \\
\hline \multicolumn{9}{|c|}{ Baseline similarity and later levels of satisfaction } \\
\hline$a_{1}$ & -0.838 & -1.135 & -0.542 & $<.001$ & -0.785 & -1.102 & -0.468 & $<.001$ \\
\hline$a_{2}$ & 0.501 & 0.292 & 0.710 & $<.001$ & 0.203 & -0.042 & 0.449 & .105 \\
\hline$a_{3}$ & 0.017 & -0.327 & 0.360 & .925 & 0.605 & 0.235 & 0.974 & .001 \\
\hline$a_{4}$ & -0.083 & -0.292 & 0.127 & .440 & 0.099 & -0.114 & 0.312 & .360 \\
\hline \multicolumn{9}{|c|}{ Baseline similarity and development of satisfaction } \\
\hline$a_{1}$ & -0.543 & -0.742 & -0.345 & $<.001$ & -0.543 & -0.742 & -0.345 & $<.001$ \\
\hline$a_{2}$ & 0.252 & 0.110 & 0.394 & $<.001$ & 0.252 & 0.110 & 0.394 & $<.001$ \\
\hline$a_{3}$ & -0.214 & -0.347 & -0.081 & .002 & -0.214 & -0.347 & -0.081 & .002 \\
\hline$a_{4}$ & -0.007 & -0.139 & 0.126 & .922 & -0.007 & -0.139 & 0.126 & .922 \\
\hline \multicolumn{9}{|c|}{ Similarity in change and development of satisfaction } \\
\hline$a_{1}$ & -1.116 & -1.316 & -0.917 & $<.001$ & -1.116 & -1.316 & -0.917 & $<.001$ \\
\hline$a_{2}$ & -0.042 & -0.166 & 0.082 & .505 & -0.042 & -0.166 & 0.082 & .505 \\
\hline$a_{3}$ & -0.312 & -0.436 & -0.189 & $<.001$ & -0.312 & -0.436 & -0.189 & $<.001$ \\
\hline$a_{4}$ & 0.352 & 0.168 & 0.536 & $<.001$ & 0.352 & 0.168 & 0.536 & $<.001$ \\
\hline
\end{tabular}

$N=2337$ couples. EST point estimate of surface parameter. $L B / U B$ Lower and upper bound of $95 \%$ confidence interval. All models are controlled for age of the participants, relationship duration, shyness, and depressiveness

relationship satisfaction of women and men $\left(\Delta \chi^{2}=15.58, \Delta d f=5, p<.001\right)$. We, thus, report the results for the unconstrained model, which is saturated. The results are displayed in the upper part of Table 3 and in Fig. 4a, b. The path coefficients, from which the surface parameters were derived, are reported in Supplemental Table S3.

For women, relationship satisfaction was higher only when she and her partner were uniformly low on loneliness, which is reflected by the significantly negative $a_{1}$-parameter (see upper part of Table 3). When couples were congruently high on loneliness, women were somewhat more satisfied than women who were congruent with their partners on medium scores of loneliness, as reflected by the significantly positive $a_{2}$-parameter (see also Fig. 4a). Incongruence in loneliness was associated with low relationship satisfaction across the entire spectrum of the scale (i.e., nonsignificant parameters $a_{3}$ and $a_{4}$; see also Fig. 4a). Thus, women are less satisfied prospectively when either partner scored higher on loneliness than the other, indicating an absence of buffering or compensatory effects. Overall, the pattern observed for women resembles a couple-oriented picture (Schönbrodt et al. 2018).

For men, in contrast, loneliness predicted later satisfaction in an actor-driven way. This means that the female partner's loneliness did not affect the male partner's relationship satisfaction (see Fig. 4b). This pattern is indicated by only the surface parameters $a_{1}$ and $a_{3}$ being significant. Thus, irrespective of the woman's degree of loneliness, men were more satisfied with their relationships when they scored low on loneliness. Men having higher levels of loneliness than others were less satisfied with their relationships 8 years later, again irrespective of their partner's loneliness (see Fig. 4b). 
(A) Similarity and Women's Satisfaction at W8

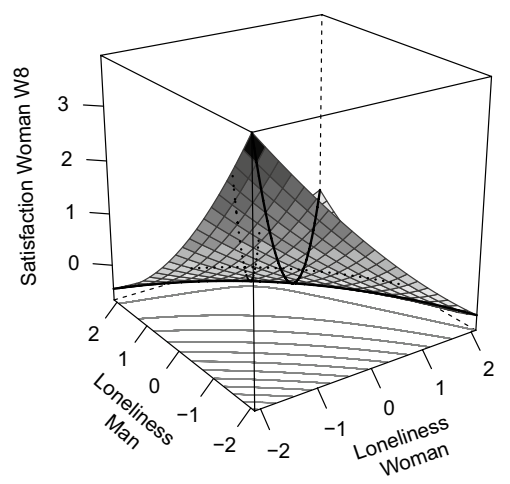

(C) Similarity and Change in Satisfaction

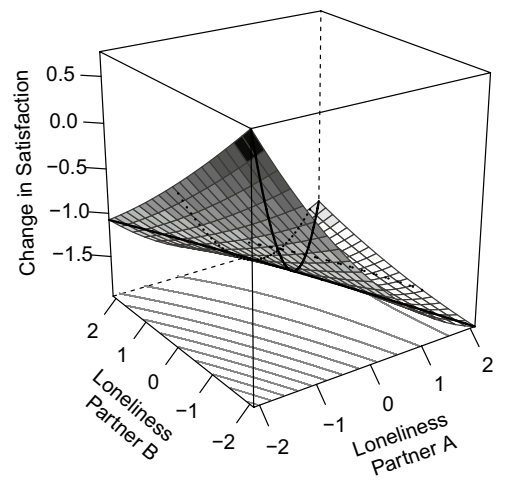

(B) Similarity and Men's Satisfaction at W8

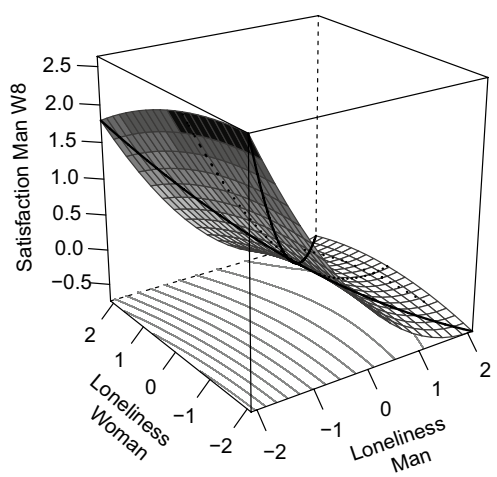

(D) Change in Loneliness and Change in Satisfaction

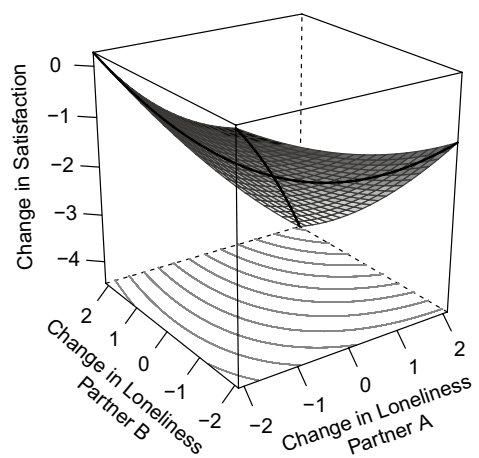

Fig. 4 Response surface plots illustrating the effect of dyadic similarity in loneliness on relationship satisfaction. Darker shades indicate lower relationship satisfaction. For colored versions and two-dimensional displays, see https://osf.io/tjuay/, where all figures are also available under a CC-BY 4.0 International licence

In the supplemental analyses on married versus unmarried couples and on couples with shorter (i.e., $<4$ years) versus longer ( $>11$ years) relationship duration, we found several differences regarding the effects of similarity in loneliness and later levels of satisfaction see Supplemental Figures S10 and S11 and model outputs at https://osf.io/ tjuay/). Specifically, differences between women and men only occurred in unmarried couples in these analyses. Furthermore, the parameter $a_{1}$ was somewhat less negative for unmarried women than for their partners (i.e., the decline in satisfaction with increasing levels of loneliness was less strong for unmarried women). The parameter $a_{2}$ was not significant for unmarried men, but for their spouses. The parameter $a_{3}$, in contrast, was negative for unmarried men but not statistically significant for their female partners. Finally, the parameter $a_{4}$ was significantly positive for unmarried men only. Despite the differences in statistical significance, however, the parameters did not differ significantly from each other. Several more differences occurred for shorter- versus longer-term relationships. In shorter-term relationships, the parameter $a_{1}$ was significantly negative for 
men, but not for women. In longer-term relationships, the pattern was reversed, that is, $a_{1}$ was significantly negative for women, but not for men. The parameter $a_{2}$ was significantly positive for women in both shorter- and longer-term relationships, but not for men. The parameter $a_{3}$ was statistically significant only for men in shorter-term relationships. For women, it tended to be positive (i.e., incongruence tended to have a positive association with later satisfaction), but did not reach statistical significance. The difference in the $a_{3}$-parameter between women and men in shorter-term relationships was itself statistically significant. The parameter $a_{4}$ was significantly positive for men in shorter-term relationships, but not for their partners.

\subsubsection{Development of Relationship Satisfaction}

In the next step, we investigated the effects of dyadic similarity in loneliness at W1 on the development of relationship satisfaction across the 8 years of the study. The constrained model did not fit worse than the unconstrained model $\left(\Delta \chi^{2}=6.4939, \Delta d f=5, p=.261\right)$, indicating that there were no differences between women and men regarding the effects of loneliness on the development of relationship satisfaction. The constrained model had an acceptable fit to the data $\left(\chi^{2} / d f=2.99 ; \mathrm{CFI}=0.952\right.$; $\left.\mathrm{RMSEA}=0.029 ; \mathrm{SRMR}=0.045\right)$.

The resulting response surface parameters are displayed in the middle portion of Table 3 and are visualized in Fig. 4c. The path coefficients from which the surface parameters were derived are displayed in Supplemental Table S3. As indicated by the significant surface parameter $a_{1}$, relationship satisfaction slightly increased during the study period if both partners were congruently low on loneliness at W1. As indicated by the significant surface parameter $a_{2}$, this trend was curvilinear so that relationship satisfaction decreased more slowly when both partners were congruently high on loneliness at W1, compared to congruence around average scores of loneliness (see Fig. 4c). The significant parameter $a_{3}$ further indicates an effect of incongruence: Relationship satisfaction decreased fastest when the actor had high levels on loneliness while the partner had low levels (see also Fig. 4c).

In the supplemental analyses, the parameter $a_{3}$ was significantly negative for unmarried couples only. That is, incongruence in loneliness between partners tended to have a negative association with changes in satisfaction over time for unmarried, but not for married couples. For couples with a relationship duration of less than 4 years, the parameter $a_{1}$ tended to be less negative than for couples being together for more than 11 years. In contrast, the parameter $a_{2}$ was significantly positive for individuals in longer-term relationships, indicating an upward bend of the LOC. No differences occurred for $a_{3}$ and $a_{4}$. Despite these differences in statistical significance, it should be noted that the surface parameters did not significantly differ between the groups (see Supplemental Figures S12 and S13 as well as the model outputs at https://osf.io/tjuay/).

\subsubsection{Development of Loneliness and Development of Relationship Satisfaction}

In the final analysis, we examined whether dyadic similarity in the development of loneliness across 8 years was associated with the development of relationship satisfaction. When comparing the constrained and the unconstrained models, the $\chi^{2}$-difference test indicated no difference in the effects between men and women $\left(\Delta \chi^{2}=10.208, \Delta d f=5, p=.07\right)$. The constrained model had a good fit to the data as indicated by a ratio of $\chi^{2}$ to df of 2.45 , a CFI of 0.948 , an RMSEA of 0.025 and an SRMR amounting to 0.037. The resulting 
surface parameters are displayed in the bottom portion of Table 3 and are visualized in Fig. 4d. The path coefficients from which the surface parameters were derived are displayed in Supplemental Table S3.

As indicated by a significantly negative $a_{1}$-parameter, relationship satisfaction decreased slowest over time when both partners showed relative decreases in loneliness over time. Furthermore, the parameters $a_{3}$ and $a_{4}$ reached statistical significance. This indicates that incongruent constellations in the development of loneliness were associated with the development of relationship satisfaction. Specifically, relationship satisfaction decreased slower when at least one partner decreased in loneliness (i.e., $a_{4}$-parameter). This trend was slightly shifted in a way that the least decreases in satisfaction were found when Partner A (the actor) strongly decreased in loneliness (i.e., $a_{3}$-parameter; see Fig. $4 \mathrm{~d}$ ).

In the supplemental analyses, several differences occurred regarding the surface parameters for the groups. Regarding marital status, gender differences occurred for unmarried but not for married couples. The strongest difference occurred for the parameter $a_{3}$, which was significantly negative for unmarried men but not for their partners. That is, incongruence in relative changes in loneliness appear to be negatively associated with the development of relationship satisfaction for unmarried men, but not unmarried women. For married couples, $a_{3}$ was significantly negative. Regarding the parameter $a_{4}$, there was a further group difference. The parameter was positive for married couples but not statistically significant for unmarried women and men. That is, the LOIC is bend upwards for married couples but shows no curvature for unmarried couples. With regard to relationship duration, gender differences in the surface parameters were found only for couples being together for less than 4 years. As found before, the parameter $a_{3}$ was significantly negative for men in such shorter-term relationships but not for their partners. Despite these differences in statistical significance, however, the parameters did not differ significantly between the groups (for details, see Supplemental Figures S14 and S15 as well as the model outputs at https://osf. io/tjuay/).

\section{Discussion}

Individuals experience loneliness when they perceive deficiencies in quantitive or qualitative asepcts of their social relationships (Ernst and Cacioppo 1999; Perlman and Peplau 1981). A large body of literature has shown that merely being in a partner relationship is accompanied by low levels of loneliness compared to not being in a relationship (Dykstra and Fokkema 2007; Flora and Segrin 2000; Green et al. 2001; Luhmann and Hawkley 2016; Stack 1998; Tornstam 1992). However, recent studies have shown that individuals can feel lonely in partner relationships that they perceive as unsatisfactory (Ayalon et al. 2013; de Jong Gierveld et al. 2009; Givertz et al. 2013; Hsieh and Hawkley 2018; Knoke et al. 2010; Moorman 2016; Stokes 2017a, b). Most of these studies are based on cross-sectional data, sampled long-term married couples, and considered loneliness only as a correlate or consequence of low relationship quality. In the present study, we have shown that loneliness can also be seen as a predictor of relationship satisfaction and its development over several years in a large and heterogeneous sample of couples. Furthermore, we have shown that the similarity in loneliness between couple members contributes to shaping the couple's relationship satisfaction over time. 


\subsection{Loneliness as a Predictor of Relationship Satisfaction}

The results of the longitudinal APIM consistently showed that loneliness is associated with both lower levels and steeper declines in relationship satisfaction over a time period of 8 years. These findings apply intra- and interpersonally: The loneliness of one person does not only affect his or her own relationship satisfaction but spills over to his or her partner as well. At the time being, we can only speculate about the processes underlying the negative association between loneliness and relationship satisfaction. The risk-regulation model, for instance, assumes that individuals who more strongly focus on and internalize signs of rejection by the partner tend to withdraw from their partner. As a result, both partners experience a lack of belongingness and emotional closeness (Murray et al. 2006). A similar mechanism might apply for loneliness as well: Individuals feeling lonely tend to be hypervigilant to cues of social threat and conflict (Cacioppo and Hawkley 2009; Spithoven et al. 2017) and to engage less in self-disclosing behavior (e.g., Wei et al. 2005). Thus, when such negative encounters are inevitably experienced with a partner, the relationship satisfaction of lonely individuals may be disproportionately eroded because they withdraw from future behaviors that may serve to enhance the intimacy of their union.

Although loneliness exerted a clear influence on future relationship functioning, loneliness is not a characteristic of the relationship itself. The correlation between couple members' loneliness was nearly zero. Thus, loneliness appears to be an individual characteristic with consequences not only for one's own future relationship satisfaction, but also the satisfaction of one's partner.

\subsection{Similarity in Loneliness and Relationship Satisfaction}

In the present study, each partner's own experience of loneliness was found to be an important contributor to future relationship satisfaction, but the dyadic constellation of loneliness within a couple bears influence on satisfaction as well. When considering the effect of loneliness at Wave 1 on future relationship satisfaction at Wave 8, a gender difference emerged: congruence in baseline loneliness was important for women's future satisfaction, but not men's. Women's future satisfaction was highest when both partners were low on loneliness, but satisfaction was also higher when both partners were high in loneliness compared to both partners having medium scores on loneliness. Incongruence in partners' loneliness was linked with less satisfaction for women. Feminist scholars have long argued that women are more relationally-oriented than men, due in part to societal expectations of femininity that emphasize this role (Gilligan 1995). As a result, women might be more responsive to partner emotions than men (Debrot et al. 2012) and their satisfaction may be more intertwined with the emotions of their partner compared to men. Congruence in loneliness may allow women to more easily detect the loneliness of her partner. and, in the case of high loneliness, either make changes in the partnership or understand her partner more fully, either of which may culminate in higher future satisfaction. However, as this is an ad-hoc interpretation of the results, more studies are required to further substantiate this line of reasoning. For men, congruence between both partners' loneliness did not have 
implications on their future relationship satisfaction in this model. Men's satisfaction was lower when they felt lonelier, regardless of how lonely their partner was.

Such gender differences, however, were not present when considering the development of loneliness and relationship satisfaction. For both men and women, relationship satisfaction increased when both partners were initially low on loneliness, but also decreased less when both partners had high compared to medium levels of loneliness. Incongruence in baseline loneliness was associated with stronger decreases in satisfaction. Decreasing loneliness in both partners preserved satisfaction, but incongruence was also beneficial: relative decreases in loneliness in one partner also helped stabilize relationship satisfaction.

These results are complex, to be certain. Generally speaking, similarity in partners' loneliness tends to prove beneficial for the development of relationship satisfaction and dissimilarity seems to be harmful, with the exception of strong decreases in loneliness in one partner. Returning to our previous discussion of the risk-regulation model, perhaps strong decreases in even one partner may prove beneficial for the couple due to their reduced sensitivity to rejection and increased inclination to engage relationship-promoting behaviors (Murray et al. 2006).

\section{Limitations}

The results of the present study warrant some caution due to some limitations. First, although we provided the first evidence for both individual and dyadic patterns of loneliness predicting relationship satisfaction over several years, we could not investigate the underlying processes due to the design of the study. While the risk-regulation model (Murray et al. 2006) might serve as a starting point, it remains an open question whether its propositions directly apply to loneliness. In a related vein, any psychological construct that influences another person's construal of the world (e.g., evaluation of the relationship), needs to manifest in overt behavior to be perceived by the partner (Mund et al. 2016). As of yet, such interpersonal behavioral correlates of loneliness are largely unknown and would be worthwhile to investigate in future research.

Second, the association between loneliness and relationship satisfaction is most likely bidirectional, containing reciprocal influences between the constructs. In the present study, we only focused on the effects of loneliness on later levels and the development of relationship satisfaction. To examine the dynamic interplay between loneliness and relationship satisfaction, it will be necessary to employ designs and analysis models capable of investigating reciprocal effects. In the present study, such models could not be applied due to the measurement regimen of the pairfam study. Specifically, loneliness has not been assessed at all measurement occasions and the measurement intervals were uneven, thus violating a crucial assumption of such models.

Third, although the present study included couples with a considerably shorter relationship duration than previous studies on this topic, the average relationship duration in the present study was 8 years. After so many years of being together, couples might already have established a relatively stable pattern of interacting with each other. Future research might thus benefit from sampling couples with even shorter relationships to examine the full dynamic interplay between loneliness and relationship satisfaction across the early years of partner relationships. 
Fourth, particularly the use of single-item measures of loneliness and relationship satisfaction constitute an important limitation (Diamantopoulos et al. 2012; Marangoni and Ickes 1989; Daniel Russell 1982). As we have argued earlier, however, such single-item measures show a considerable amount of validity with a nomological net virtually invariant across age and overlap with multi-item scales (e.g., Lasgaard et al. 2016; Mund and Neyer 2019; Dan Russell et al. 1978; von Soest et al. 2020). Nevertheless, single-item measures are probably less reliable (Daniel Russell 1982; Marangoni and Ickes 1989; Diamantopoulos et al. 2012). and might have less variance than multi-item instruments, which might have affected the results of the DRSA. Thus, it will be important to replicate the findings reported here with multi-item instruments in future studies.

Fifth, in the present study, we focused on the long-term effects of loneliness in enduring relationships to closely parallel prior research on loneliness in partner relationships (Ayalon et al. 2013; de Jong Gierveld et al. 2009; Givertz et al. 2013; Knoke et al. 2010; Hsieh and Hawkley 2018; Moorman 2016; Stokes 2017a, b). In addition, it would be worthwhile to investigate to what extent individual levels in loneliness as well as similarity in loneliness between partners might also be predictive for relationship dissolution.

\section{Conclusion}

The results of the present study demonstrate that loneliness predicts lower levels and faster decreases in relationship satisfaction for both partners of a couple across a time period of 8 years. However, the unique dyadic combination of both partners' loneliness was found to, at least partly, mitigate these negative effects of loneliness. Such findings underscore the complexity inherent in a truly dyadic exploration of how individual characteristics impact couple relations. It is not only each partner's degree of loneliness, but the extent to which partners loneliness align with one another that is consequential for their future relationship quality. Such alignment may have differential consequences when considering a single time point compared to changes over time. These findings are of importance for theorizing couple relations to more fully account for the ways in which similarity and dissimilarity between partners' individual characteristics may contribute to the realization of lasting love.

Acknowledgements Open Access funding provided by Projekt DEAL. This paper uses data from the German Family Panel pairfam, coordinated by Josef Brüderl, Karsten Hank, Johannes Huinink, Bernhard Nauck, Franz J. Neyer, and Sabine Walper. Pairfam is funded as long-term project by the German Research Foundation (Deutsche Forschungsgemeinschaft, DFG).

Funding Preparation of this paper was partially supported by German Research Foundation Grant MU 4338/1-1 awarded to Marcus Mund.

\section{Compliance with ethical standards}

Conflicts of interest The authors declared no potential conflicts of interest with respect to the research, authorship, and/or publication of this article.

Open Access This article is licensed under a Creative Commons Attribution 4.0 International License, which permits use, sharing, adaptation, distribution and reproduction in any medium or format, as long as you give appropriate credit to the original author(s) and the source, provide a link to the Creative Commons licence, and indicate if changes were made. The images or other third party material in this article are included in the article's Creative Commons licence, unless indicated otherwise in a credit line to the 
material. If material is not included in the article's Creative Commons licence and your intended use is not permitted by statutory regulation or exceeds the permitted use, you will need to obtain permission directly from the copyright holder. To view a copy of this licence, visit http://creativecommons.org/licenses/by/4.0/.

\section{References}

Asendorpf, J. B. (1990). Beyond social withdrawal: Shyness, unsociability, and peer avoidance. Human Development, 33, 250-259. https://doi.org/10.1159/000276522.

Ayalon, L., Shiovitz-Ezra, S., \& Palgi, Y. (2013). Associations of loneliness in older married men and women. Aging \& Mental Health, 17, 33-39. https://doi.org/10.1080/13607863.2012.702725.

Baumeister, R. F., \& Leary, M. R. (1995). The need to belong: Desire for interpersonal attachment as a fundamental human motivation. Psychological Bulletin, 117, 497-529. https://doi. org/10.1037/0033-2909.117.3.497.

Bosma, H., Jansen, M., Schefman, S., Hajema, K. J., \& Feron, F. (2015). Lonely at the bottom: A crosssectional study on being ill, poor, and lonely. Public Health, 129, 185-187. https://doi.org/10.1016/j. puhe.2014.11.016.

Brüderl, J., Hank, K., Huinink, J., Nauck, B., Neyer, F. J., Walper, S., \& Wilhelm, B. (2017). The German Family Panel (pairfam): Za5678 data file version 8.0.0. Cologne: GESIS Data Archive. https://doi. org/10.4232/pairfam.5678.8.0.0

Cacioppo, J. T., \& Hawkley, L. C. (2009). Perceived social isolation and cognition. Trends in Cognitive Sciences, 13, 447-454. https://doi.org/10.1016/j.tics.2009.06.005.

de Jong Gierveld, J., Broese van Groenou, M., Hoogendoorn, A. W., \& Smit, J. H. (2009). Quality of marriages in later life and emotional and social loneliness. The Journals of Gerontology: Series B, 64B, 497-506. https://doi.org/10.1093/geronb/gbn043.

Debrot, A., Cook, W. L., Perrez, M., \& Horn, A. B. (2012). Deeds matter: Daily enacted responsiveness and intimacy in couples' daily lives. Journal of Family Psychology, 26, 617-627. https://doi. org/10.1037/a0028666.

Diamantopoulos, A., Sarstedt, M., Fuchs, C., Wilczynski, P., \& Kaiser, S. (2012). Guidelines for choosing between multi-item and single-item scales for construct measurement: A predictive validity perspective. Journal of the Academy of Marketing Science, 40, 434-449. https://doi.org/10.1007/ s11747-011-0300-3.

Dykstra, P. A., \& Fokkema, T. (2007). Social and emotional loneliness among divorced and married men and women: Comparing the deficit and cognitive perspectives. Basic and Applied Social Psychology, 29, 1-12. https://doi.org/10.1080/01973530701330843.

Dyrenforth, P. S., Kashy, D. A., Donnellan, M. B., \& Lucas, R. E. (2010). Predicting relationship and life satisfaction from personality in nationally representative samples from three countries: The relative importance of actor, partner, and similarity effects. Journal of Personality and Social Psychology, 99, 690-702. https://doi.org/10.1037/a0020385.

Edwards, J. R. (1993). Problems with the use of profile similarity indices in the study of congruence in organizational research. Personnel Psychology, 46, 641-665. https://doi. org/10.1111/j.1744-6570.1993.tb00889.x.

Enders, C. K. (2010). Applied missing data analysis. New York: Guilford Press.

Ernst, J. M., \& Cacioppo, J. T. (1999). Lonely hearts: Psychological perspectives on loneliness. Applied and Preventive Psychology, 8, 1-22. https://doi.org/10.1016/S0962-1849(99)80008-0.

Flora, J., \& Segrin, C. (2000). Relationship development in dating couples: Implications for relational satisfaction and loneliness. Journal of Social and Personal Relationships, 17, 811-825. https://doi. org/10.1177/0265407500176006.

Fridhandler, B. M. (1986). Conceptual note on state, trait, and the state-trait distinction. Journal of Personality and Social Psychology, 50, 169-174. https://doi.org/10.1037/0022-3514.50.1.169.

Gilligan, C. (1995). Hearing the difference: Theorizing connection. Hypatia, 10, 120-127. https://doi. org/10.1111/j.1527-2001.1995.tb01373.x.

Givertz, M., Woszidlo, A., Segrin, C., \& Knutson, K. (2013). Direct and indirect effects of attachment orientation on relationship quality and loneliness in married couples. Journal of Social and Personal Relationships, 30, 1096-1120. https://doi.org/10.1177/0265407513482445.

Gonzaga, G. C., Campos, B., \& Bradbury, T. (2007). Similarity, convergence, and relationship satisfaction in dating and married couples. Journal of Personality and Social Psychology, 93, 34-48. https ://doi.org/10.1037/0022-3514.93.1.34. 
Goossens, L., van Roekel, E., Verhagen, M., Cacioppo, J. T., Cacioppo, S., Maes, M., et al. (2015). The genetics of lonelienss: Linking evolutionary theory to genome-wide genetics, epigenetics, and social science. Perspectives on Psychological Science, 10, 213-226. https://doi.org/10.1177/17456 91614564878.

Green, L. R., Richardson, D. S., Lago, T., \& Schatten-Jones, E. C. (2001). Network correlates of social and emotional loneliness in young and older adults. Personality and Social Psychology Bulletin, 27, 281-288. https://doi.org/10.1177/0146167201273002.

Hawkley, L. C., \& Cacioppo, J. T. (2010). Loneliness matters: A theoretical and empirical review of consequences and mechanisms. Annals of Behavioral Medicine, 40, 218-227. https://doi.org/10.1007/ s12160-010-9210-8.

Heinrich, L. M., \& Gullone, E. (2006). The clinical significance of loneliness: A literature review. Clinical Psychology Review, 26, 695-718. https://doi.org/10.1016/j.cpr.2006.04.002.

Hendrick, S. S., Dicke, A., \& Hendrick, C. (1998). The Relationship Assessment Scale. Journal of Social and Personal Relationships, 15, 137-142. https://doi.org/10.1177/0265407598151009.

Holt-Lunstad, J., Smith, T. B., Baker, M., Harris, T., \& Stephenson, D. (2015). Loneliness and social isolation as risk factors for mortality: A meta-analytic review. Perspectives on Psychological Science, 10, 227-237. https://doi.org/10.1177/1745691614568352.

Hsieh, N., \& Hawkley, L. C. (2018). Loneliness in the older adult marriage: Associations with dyadic aversion, indifference, and ambivalence. Journal of Social and Personal Relationships, 35, 13191339. https://doi.org/10.1177/0265407517712480.

Hughes, M. E., Waite, L. J., Hawkley, L. C., \& Cacioppo, J. T. (2004). A short scale for measuring loneliness in large surveys: Results from two population-based studies. Research on Aging, 26, 655672. https://doi.org/10.1177/0164027504268574.

Huinink, J., Brüderl, J., Nauck, B., Walper, S., Castiglioni, L., \& Feldhaus, M. (2011). Panel analysis of intimate relationships and family dynamics (pairfam): Conceptual framework and design. Zeitschrift für Familienforschung, 23, 77-101.

Iecovich, E. (2013). Psychometric properties of the Hebrew version of the de Jong Gierveld Loneliness Scale. Educational Gerontology, 39, 12-27. https://doi.org/10.1080/03601277.2012.660860.

Jo Cox Commission on Loneliness. (2017). Combating loneliness one conversation at a time: A call to action. London: Jo Cox Commission on Loneliness. Retrieved February 15, 2020 from https://www.ageuk.org. uk/globalassets/age-uk/documents/reports-and-publications/reports-and-briefings/active-communities/ rb_dec17_jocox_commission_finalreport.pdf.

Johnson, M. D., Galambos, N. L., Finn, C., Neyer, F. J., \& Horne, R. M. (2017). Pathways between self-esteem and depression in couples. Developmental Psychology, 53, 787-799. https://doi.org/10.1037/dev0000276.

Johnson, M. D., Horne, R. M., Hardy, N. R., \& Anderson, J. R. (2018). Temporality of couple conflict and relationship perceptions. Journal of Family Psychology, 32, 445-455. https://doi.org/10.1037/fam0000398.

Kenny, D. A., Kashy, D. A., \& Cook, W. L. (2006). Dyadic data analysis. New York: Guilford Press.

Knoke, J., Burau, J., \& Roehrle, B. (2010). Attachment styles, loneliness, quality, and stability of marital relationships. Journal of Divorce \& Remarriage, 51, 310-325. https://doi.org/10.1080/10502551003652017.

Kraemer, H. C., Gullion, C. M., Rush, A. J., Frank, E., \& Kupfer, D. J. (1994). Can state and trait variables be disentangled? A methodological framework for psychiatric disorders. Psychiatry Research, 52, 55-69. https://doi.org/10.1016/0165-1781(94)90120-1.

Lasgaard, M., Friis, K., \& Shevlin, M. (2016). Where are all the lonely people? A population-based study of high-risk groups across the life span. Social Psychiatry and Psychiatric Epidemiology, 51, 1373-1384. https://doi.org/10.1007/s00127-016-1279-3.

Leikas, S., Ilmarinen, V.-J., Verkasalo, M., Vartiainen, H.-L., \& Lönnqvist, J.-E. (2018). Relationship satisfaction and similarity of personality traits, personal values, and attitudes. Personality and Individual Differences, 123, 191-198. https://doi.org/10.1016/j.paid.2017.11.024.

Luhmann, M., \& Hawkley, L. C. (2016). Age differences in loneliness from late adolescence to oldest old age. Developmental Psychology, 52, 943-959. https://doi.org/10.1037/dev0000117.

Marangoni, C., \& Ickes, W. (1989). Loneliness: A theoretical review with implications for measurement. Journal of Social and Personal Relationships, 6, 93-128. https://doi.org/10.1177/026540758900600107.

McCrae, R. R., \& Costa, P. T. (2008). The Five-Factor Theory of personality. In O. P. John, R. W. Robins, \& L. A. Pervin (Eds.), Handbook of personality: Theory and research (3rd ed., pp. 159-181). New York: Guilford Press.

McNeish, D. (2018). Thanks coefficient alpha, we'll take it from here. Psychological Methods, 23, 412-433. https://doi.org/10.1037/met0000144.

Moorman, S. M. (2016). Dyadic perspectives on marital quality and loneliness in later life. Journal of Social and Personal Relationships, 33, 600-618. https://doi.org/10.1177/0265407515584504. 
Mund, M., Finn, C., Hagemeyer, B., \& Neyer, F. J. (2016). Understanding dynamic transactions between personality traits and partner relationships. Current Directions in Psychological Science, 25, 411-416. https:// doi.org/10.1177/0963721416659458.

Mund, M., Freuding, M. M., Möbius, K., Horn, N., \& Neyer, F. J. (2020). The stability and change of loneliness across the lifespan: A meta-analysis of longitudinal studies. Personality and Social Psychology Review, 24, 24-52. https://doi.org/10.1177/1088868319850738.

Mund, M., Lüdtke, O., \& Neyer, F. J. (2019). Owner of a lonely heart: The stability of loneliness across the life span. Journal of Personality and Social Psychology. https://doi.org/10.1037/pspp0000262.

Mund, M., \& Neyer, F. J. (2019). Loneliness effects on personality. International Journal of Behavioral Development, 43, 136-146. https://doi.org/10.1177/0165025418800224.

Murray, S. L., Holmes, J. G., \& Collins, N. L. (2006). Optimizing assurance: The risk regulation system in relationships. Psychological Bulletin, 132, 641-666. https://doi.org/10.1037/0033-2909.132.5.641.

Neyer, F. J., Mund, M., Zimmermann, J., \& Wrzus, C. (2014). Personality-relationship transactions revisited. Journal of Personality, 82, 539-550. https://doi.org/10.1111/jopy.12063.

Patterson, A. C., \& Veenstra, G. (2010). Loneliness and risk of mortality: A longitudinal investigation in alameda county, california. Social Science \& Medicine, 71, 181-186. https://doi.org/10.1016/j.socsc imed.2010.03.024.

Perlman, D., \& Peplau, L. A. (1981). Toward a social psychology of loneliness. In N. Duck \& R. Gilmour (Eds.), Personal relationships in disorder (pp. 31-56). London: Academic Press.

Pinquart, M., \& Sörensen, S. (2001). Influences on loneliness in older adults: A meta-analysis. Basic and Applied Social Psychology, 23, 245-266.

R Core Team. (2018). R: A language and environment for statistical computing. Vienna: R Foundation for Statistical Computing. Retrieved February 15, 2020 from http://www.r-project.org.

Ram, N., \& Grimm, K. J. (2007). Using simple and complex growth models to articulate developmental change: Matching theory to method. International Journal of Behavioral Development, 31, 303-316. https://doi. org/10.1177/0165025407077751.

Rhoades, G. K., Stanley, S. M., \& Markman, H. J. (2012). The impact of the transition to cohabitation on relationship functioning: Cross-sectional and longitudinal findings. Journal of Family Psychology, 26, 348358. https://doi.org/10.1037/a0028316.

Rosseel, Y. (2012). lavaan: An R package for structural equation modeling. Journal of Statistical Software, 48, $1-36$.

Russell, D. (1982). The measurement of loneliness. In L. A. Pervin \& D. Perlman (Eds.), Loneliness: A sourcebook of current theory, research and therapy (pp. 81-104). New York: Wiley.

Russell, D., Peplau, L. A., \& Ferguson, M. L. (1978). Developing a measure of loneliness. Journal of Personality Assessment, 42, 290-294. https://doi.org/10.1207/s15327752jpa4203_11.

Schermelleh-Engel, K., Moosbrugger, H., \& Müller, H. (2003). Evaluating the fit of structural equation models: Tests of significance and descriptive goodness-of-fit measures. Methods of Psychological Research Online, 8, 23-74.

Schönbrodt, F. D. (2017). RSA: An R package for response surface analysis (version 0.9.11). Retrieved May 30 , 2018 from https://cran.r-project.org/package=RSA.

Schönbrodt, F. D., Humberg, S., \& Nestler, S. (2018). Testing similarity effects with dyadic response surface analysis. European Journal of Personality, 32, 627-641. https://doi.org/10.1002/per.2169.

Shiovitz-Ezra, S., \& Ayalon, L. (2010). Situational versus chronic loneliness as risk factors for all-cause mortality. International Psychogeriatrics, 22, 455-462. https://doi.org/10.1017/S1041610209991426.

Spithoven, A. W. M., Bijttebier, P., \& Goossens, L. (2017). It is all in their mind: A review on information processing bias in lonely individuals. Clinical Psychology Review, 58, 97-114. https://doi.org/10.1016/j. cpr.2017.10.003.

Spithoven, A. W. M., Cacioppo, S., Goossens, L., \& Cacioppo, J. T. (2019). Genetic contributions to loneliness and their relevance to the evolutionary theory of loneliness. Perspectives on Psychological Science, 14, 376-396. https://doi.org/10.1177/174569161881268.

Stack, S. (1998). Marriage, family, and loneliness: A cross-national study. Sociological Perspectives, 41, 415432. https://doi.org/10.2307/1389484.

Statistisches Bundesamt. (2016). Bevölkerung und erwerbstätigkeit: Zusammenfassende übersichten eheschließungen, geborene und gestorbene 1946-2015 [Population and employment: Summarizing overviews over marriages, births, and deaths 1946-2015]. Wiesbaden: Statistisches Bundesamt.

Stokes, J. E. (2017a). Marital quality and loneliness in later life: A dyadic analysis of older married couples in Ireland. Journal of Social and Personal Relationships, 34, 114-135. https://doi.org/10.1177/0265407515 626309. 
Stokes, J. E. (2017b). Two-wave dyadic analysis of marital quality and loneliness in later life: Results from the Irish Longitudinal Study on Ageing. Research on Aging, 39, 635-656. https://doi.org/10.1177/01640 27515624224.

Tornstam, L. (1992). Loneliness in marriage. Journal of Social and Personal Relationships, 9, 197-217. https:// doi.org/10.1177/0265407592092003.

van Scheppingen, M. A., Chopik, W. J., Bleidorn, W., \& Denissen, J. J. A. (2019). Longitudinal actor, partner, and similarity effects of personality on well-being. Journal of Personality and Social Psychology, 117, e51-e70. https://doi.org/10.1037/pspp0000211.

von Soest, T., Luhmann, M., Hansen, T., \& Gerstorf, D. (2020). Development of loneliness in midlife and old age: Its nature and correlates. Journal of Personality and Social Psychology, 118, 388-406. https://doi. org/10.1037/pspp0000219.

Watson, D., Klohnen, E. C., Casillas, A., Nus Simms, E., Haig, J., \& Berry, D. S. (2004). Match makers and deal breakers: Analyses of assortative mating in newlywed couples. Journal of Personality, 72, 10291068. https://doi.org/10.1111/j.0022-3506.2004.00289.x.

Wei, M., Russell, D. W., \& Zakalik, R. A. (2005). Adult attachment, social self-efficacy, self-disclosure, loneliness, and subsequent depression for freshmen college students: A longitudinal study. Journal of Counseling Psychology, 52, 602-614. https://doi.org/10.1037/0022-0167.52.4.602.

Weidmann, R., Ledermann, T., \& Grob, A. (2016). The interdependence of personality and satisfaction in couples: A review. European Psychologist, 21, 284-295. https://doi.org/10.1027/1016-9040/a000261.

Weidmann, R., Schönbrodt, F. D., Ledermann, T., \& Grob, A. (2017). Concurrent and longitudinal dyadic polynomial regression analysis of big five traits and relationship satisfaction: Does similarity matter? Journal of Research in Personality, 70, 6-15. https://doi.org/10.1016/j.jrp.2017.04.003.

Zhou, Y., Wang, K., Chen, S., Zhang, J., \& Zhou, M. (2017). An exploratory investigation of the role of openness in relationship quality among emerging adult Chinese couples. Frontiers in Psychology, 8, 382. https ://doi.org/10.3389/fpsyg.2017.00382.

Publisher's Note Springer Nature remains neutral with regard to jurisdictional claims in published maps and institutional affiliations. 